1938 by the Earl of Athlone, the Nurses' Home in 1938 by Queen Mary, and finally the Hospital was declared open by the Hospital Patron, H.M. George VI, accompanied by Queen Elizabeth, in May 1939.

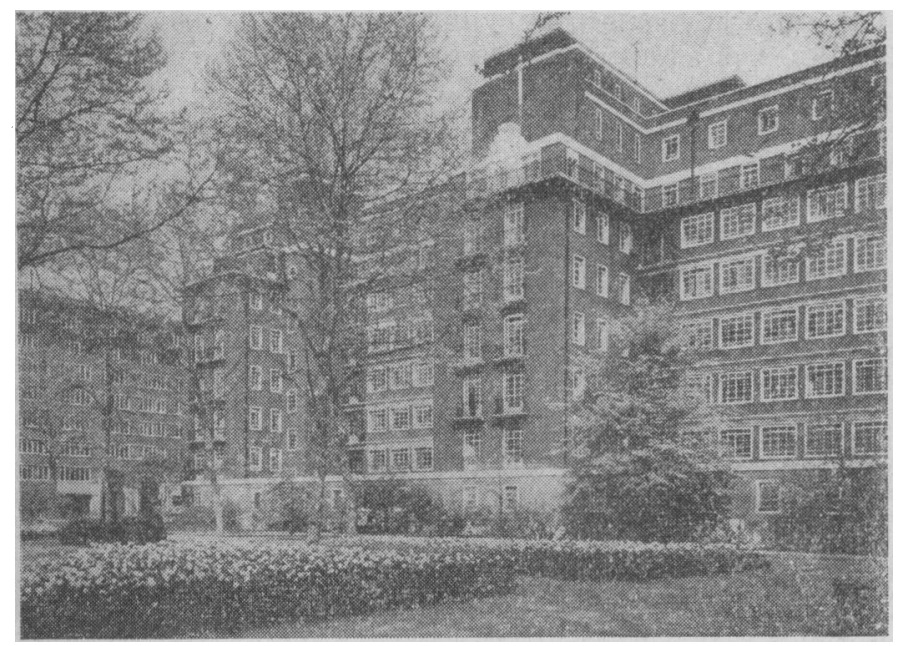

Westminster Hospital, 1966.

The Hospital had hardly been opened when the second world war began. During this period the building, though struck by bombs on two occasions in 1940 and heavily blasted by a land mine in April 1941, continued to serve its functions throughout. So, too, the School functioned vigorously during the war, even though the preclinical students had been evacuated in the early years, at first to Glasgow and later to Birmingham.

\section{Post-war Period}

Westminster's post-war history continued steadily until 1948, when, after the inauguration of the National Health Act, certain hospitals were "designated" to form part of the West- minster Group of Hospitals. This now comprised Westminster Hospital, the Gordon Hospital, Westminster Children's Hospital, and All Saints' Hospital, Lambeth.

In 1960 Queen Mary's Hospital, Roehampton, was added to the Group, which now comprises 1,090 beds-a far cry from the original 12.

A most poignant moment in the history of the Hospital occurred in late 1951. This was the operation on the Hospital Patron, George VI, which was carried out by Sir Clement Price Thomas and a team of surgeons, anaesthetists, and nurses from the Hospital. The beautiful memorial window to His Majesty's memory in the Hospital Chapel bears their names.

In 1958 the Wolfson Trust advanced $£ 250,000$ to bulld a Nurses' Training School in Vincent Square, and this magnificent building was opened on 23 March 1960 by the Queen Mother. A feature of this building is the beautiful library named in memory of the late Edwina Lady Mountbatten, who had served as a V.A.D. nurse in the Hospital during the war.

At the present time the completion of a new wing to be linked to the main Hospital by a multi-story bridge is eagerly awaited. This building will contain space for the professorial units of medicine, surgery, chemical pathology, anaesthesia, and the projected unit in obstetrics and gynaecology. There will also be housed there certain special departments. It is felt that completion of this building will enable the Hospital and School to maintain their place in the forefront as a centre for research, the teaching of students and nurses, and last, but not least, the purpose for whi-h it was founded-the treatment of patients.

The author wishes to acknowledge most gratefully the assistance he has received throughout from Dr. Peter Hansell and the devoted staff of his Department of Medical Photography and Illustration.

The original source material for this article will be found in a book entitled Westminster Hospital 1716-1966, written by the author and illustrated by Dr. Hansell. This book, produced under the auspices of the Board of Governors, will be published shortly by Pitman Medical Publishing Company.

\title{
Mountain Accidents and Mountain Rescue in Great Britain
}

\author{
N. F. KIRKMAN,* M.D., F.R.C.S.
}

Brit. med. F., 1966, 1, 162-164

In these days of increasing leisure many more people than formerly are going to the hills for recreation and exercise. This is especially true of the young. Courses and expeditions organized by schools, climbing schools, Outward Bound schools, the Duke of Edinburgh Award Scheme, Rover and Scout groups, and other youth groups are now being held daily throughout most months of the year. In addition, the number of walking, rambling, and mountaineering clubs continues to grow. The access to mountainous areas has been made easier by the advent of the motorways and improved transport facilities. As a result of these changes the number of people visiting the Lake District, Snowdonia, the Pennines, and Scotland has probably increased tenfold in the last 20 years.

This increase in numbers has brought an increase in the number of accidents and acute illness taking place in the hills. There are now probably nearly 200 cases in England and Wales and 60 in Scotland (excluding skiing accidents) occurring annually.
Many of the public who frequent the hills and many doctors are unaware of the facilities which already exist to deal with these emergencies (B.M.f., 1964).

The police are basically responsible for the care of injured persons, but they are not as a rule equipped or trained for mountain rescue, though they have rendered great help on occasions. They have been especially helpful in organizing rescues, calling out rescue teams, and assisting with transport and telecommunications. In some of the climbing centres in Wales and Scotland mountain-rescue teams have recently included a few policemen in their ranks.

\section{Mountain-rescue Services}

The problem of first aid for mountain casualties has long been recognized by the mountaineering clubs of Great Britain.

* Issuing Officer for Morphia and Equipment Officer of the Mountain Rescue Committee. 
In 1936 they formed the Mountain Rescue Committee to organize mountain-rescue posts, first aid, and transport of casualties in the chief climbing centres. Since 1949 the Ministry of Health and the Home Office have recognized this committee. Authorized equipment at official mountain-rescue posts is now paid for by the National Health Service, but the costs of special equipment, climbing aids, insurance of rescuers, and clerical work are the responsibility of the Mountain Rescue Committee. On the advice of the committee and its Scottish branch new posts may be set up when the need for them has been shown to exist. The committee is now formed by representatives from the mountaineering clubs of Great Britain, other outdoor organizations-such as Youth Hostel Associations, mountain schools, the Ramblers Association-the police in Scotland, and also representatives from mountain-rescue teams.

Most of the busy mountain-rescue posts are supervised by a local mountain-rescue team. These teams are formed of volunteers, some of whom take the British Red Cross or St. John's first-aid certificates. The formation of local rescue teams has increased the efficiency of first aid and transport of the injured climbers and walkers; some old-established teams have many notable rescues to their credit.

There are now 59 official mountain-rescue posts in Great Britain at strategic centres in mountainous areas. Their situation is shown by a blue and white plaque (Fig. 1) attached to

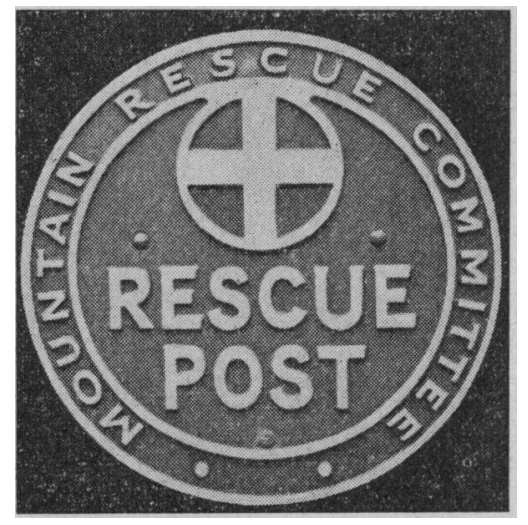

FIG. 1.-Official sign of mountain-rescue
post.

the building where the equipment is kept. Some of the older posts are marked on the 1 in. ordnance survey map, but at times posts are moved. The exact situation of an official mountainrescue post may be found by consulting the current edition of the Mountain Rescue and Cave Rescue handbook (Mountain Rescue Committee, 1965).

\section{Equipment of Mountain-rescue First-aid Posts}

The standard equipment of official mountain-rescue first-aid posts includes a stretcher. In most posts this is a Thomas stretcher designed by Eustace Thomas, a distinguished climber and engineer. It is made from duralumin tubing, has telescopic handles, ash or laminated skids, and it is fitted with a Terylene net bed (Fig. 2). This stretcher has proved itself over many years. In Scotland the Duff and MacInnes stretchers have also been used. Both these stretchers are made in two parts which may be carried separately and united at the scene of the accident.

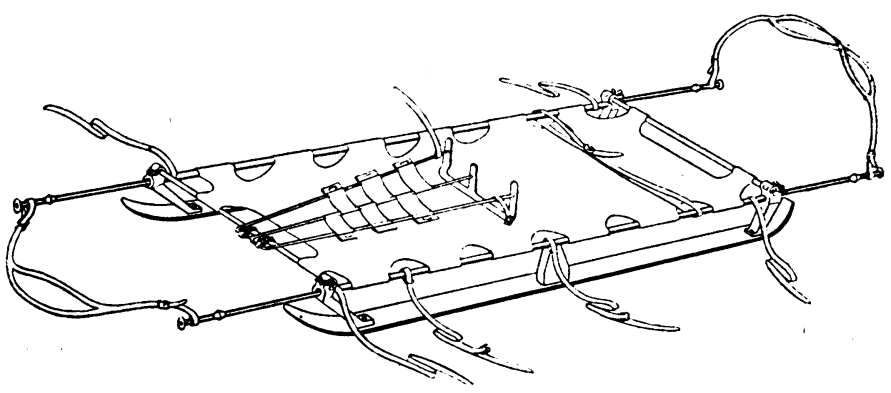

Fig. 2.-Thomas stretcher, with double Thomas splint.

Morphine (Omnopon gr. $\frac{1}{2}$ in a Tubunic ampoule-syringe) is standard equipment at all official posts and its safe custody is the responsibility of the post supervisor. In all cases where morphine is used details are recorded and reported annually to the Home Office by the Issuing Officer for Morphia.

The kit, carried in two rucksacks, also includes antiseptics, bandages, arm splints, and a casualty bag. The casualty bag is a waterproofed, quilted sleeping-bag with a plastic-foam base into which the casualty is placed for transport. All official rescue kits include means of providing hot drinks, such as Thermos flasks and pressure stoves at isolated posts. Self-heating tins of soup have been most useful both for the victim and rescuers during prolonged rescues and searches.

Besides this civilian organization, the R.A.F. Mountain Rescue Service has played a great part in mountain rescue since its formation in the last war, notably in Scotland and North Wales. The units are of course superbly equipped and freely mobile and help has often been given to accident victims far from R.A.F. bases. The British Red Cross and St. John's Ambulance Brigade also maintain first-aid boxes in the Lake district and Scotland.

\section{Mountain Accidents in 1963 and 1964}

The details of mountain accidents given here have been compiled from accident reports submitted to the Mountain Rescue Committee. While more accidents may have taken place than are recorded here, the great majority of accidents occurring in the mountains of England and Wales and most of those in Scotland, excluding skiing accidents, are recorded. The type of injury and cause of the accident have been roughly classified. All official posts are given accident report forms which enable the supervisor of the post to request replacements of equipment used in the accident and to give details of the person injured and how the accident occurred. Needless to say, not all accident report forms are filled in completely, but in most cases adequate details are given (Table $\mathrm{I}$ ).

In addition, 54 skiing accidents were reported in 1963, but probably three times as many occurred. Nine people were

Tabie I.-Analysis of Mountain Accidents in 1963 and 1964

\begin{tabular}{|c|c|c|c|c|c|c|c|c|c|c|c|c|c|c|}
\hline \multirow{2}{*}{\multicolumn{3}{|c|}{ Accidents }} & \multicolumn{2}{|c|}{ Wales } & \multicolumn{2}{|c|}{ Lake District } & \multicolumn{2}{|c|}{ Pennines } & \multicolumn{2}{|c|}{ Scotland } & \multicolumn{2}{|c|}{ Other Areas } & \multicolumn{2}{|c|}{ Totals } \\
\hline & & & 1963 & 1964 & 1963 & 1964 & 1963 & 1964 & 1963 & 1964 & 1963 & 1964 & 1963 & 1964 \\
\hline $\begin{array}{l}\text { Totals } \\
\text { Injured } \\
\text { Fatal }\end{array}$ & $\because$. & $\because$ & $\begin{array}{r}44 \\
39 \\
5 \\
\end{array}$ & $\begin{array}{r}36 \\
31 \\
5 \\
\end{array}$ & $\begin{array}{r}70 \\
65 \\
5 \\
\end{array}$ & $\begin{array}{r}55 \\
49 \\
6 \\
\end{array}$ & $\begin{array}{r}16 \\
11 \\
5\end{array}$ & $\begin{array}{r}15 \\
11 \\
4\end{array}$ & $\begin{array}{r}28 \\
25 \\
3\end{array}$ & $\begin{array}{l}50 \\
37 \\
13\end{array}$ & $\begin{array}{l}2 \\
1 \\
1\end{array}$ & $\begin{array}{l}3 \\
2 \\
1\end{array}$ & $\begin{array}{r}160 \\
141 \\
19\end{array}$ & $\begin{array}{r}159 \\
130 \\
29 \\
\end{array}$ \\
\hline $\begin{array}{l}\text { Walking } \\
\text { Climbing } \\
\text { Caving } \\
\text { Unknown }\end{array}$ & $\begin{array}{l}\ddot{ } \\
\ddot{.}\end{array}$ & $\begin{array}{l}\because \\
\because \\
.\end{array}$ & $\begin{array}{l}15(3)^{*} \\
29(2) \\
-\end{array}$ & $\begin{array}{l}11(2) \\
23(3) \\
=\end{array}$ & $\begin{array}{l}47(4) \\
23(1) \\
=\end{array}$ & $\begin{array}{l}34(1) \\
21(5) \\
=\end{array}$ & $\begin{array}{l}3(1) \\
7(3) \\
6(1) \\
-\end{array}$ & $\begin{array}{l}9(3) \\
2 \\
4(1) \\
-\end{array}$ & $\frac{6}{13}^{6(1)}$ & $\begin{array}{l}21(4) \\
12(5) \\
\frac{17}{17}(4)\end{array}$ & $\frac{1}{1}^{(1)}$ & $\frac{1}{2}^{(1)}$ & $\begin{array}{r}72 \\
68 \\
7 \\
13\end{array}$ & $\begin{array}{r}76 \\
60 \\
17\end{array}$ \\
\hline
\end{tabular}

- Figures in parentheses indicate fatal injuries. 
caught in avalanches, three being killed in the Pennines in the early part of 1963 as a result of the extraordinary snow conditions. Several climbers were injured when pitons (pegs) were pulled out during falls. In one case the falling climber dragged out four and in another he was struck on the head by his piton hammer as he fell.

Tables II and III show the nature of the injuries suffered during the two years, and, for 1964, the cause of the accidents. As far as possible the major cause of the accident is given.

TABLE II.-Analysis of Injuries Due to Mountain Accidents in 1963 and 1964

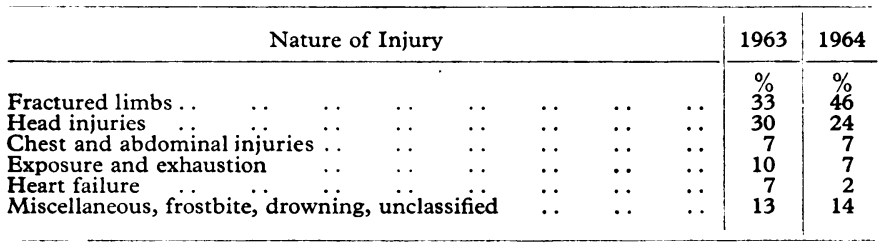

TABLE III.-Causes of Mountain Accidents in 1964

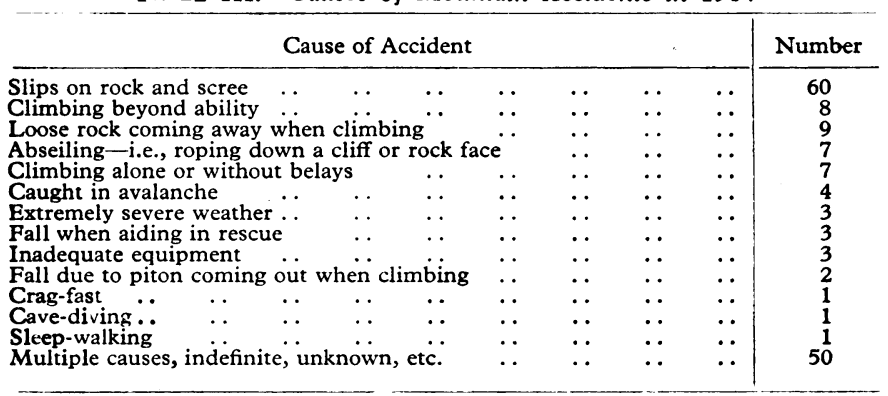

More than half of the persons injured on the hills of Great Britain in 1964 were 21 or less.

Besides dealing with these accidents rescue teams have been called out on many occasions to search for missing persons and rescue crag-fast walkers, who have eventually been rescued or found uninjured. These cases are excluded from the accident statistics.

\section{Comments}

It will be noted that these mountain accidents are distributed more or less equally between walkers and climbers. Head injuries make up about a quarter of the total. If climbers could be persuaded to wear helmets similar to industrial helmets many of these injuries, which are so often fatal, might be avoided. The British Mountaineering Council and the International Committee for Alpine Rescue (I.K.A.R.) and the Union Internationale des Associations d'Alpinisme (U.I.A.A.) are investigating suitable designs for a climber's helmet.

Fractures usually involve the lower limbs. A double Thomas splint is most often used for immobilizing these fractures. As both legs are secured in this splint it is very useful when the patient has to be lowered down a cliff during the rescue and it is essential for him to be firmly strapped in. Kramer wire splinting is used at some posts as a first-aid splint and inflatable jet splints which fit over the boot and trousers have recently been found effective and comfortable.

Cases of exposure and exhaustion continue to occur in increasing numbers, especially among the young. Recently valuable papers on these problems have appeared in both the medical and mountaineering literature. Pugh (1964), Edholm (1963), and Edholm et al. (1964) have given details of the importance of maintaining the body core heat and stressed the need for adequate clothing, insulation, and food to prevent exposure, and how it should be treated by the proper application of adequate heat.

The Mountain Rescue Committee keeps the equipment used under review and considers suggestions and modifications which might prove helpful. Experience has shown that simplicity of design and good wearing and keeping qualities are of great importance in all equipment to be used in mountain-rescue kits.

The administration of morphine by first-aid personnel has been amply justified in practice by the experience of hundreds of persons injured in the hills. As in mine injuries, where morphine may be administered by lay persons, six, 12 , or more hours may elapse after injury before the injured person is admitted to hospital. Strong warnings are given to users of official mountain-rescue equipment against the use of morphine in cases of head injury or unconsciousness, and to date no case of overdosage or misuse has been recorded.

Radiotelecommunication, now that transistorized instruments are available, is being used at busy posts by some rescue teams. The R.A.F. have used walkie-talkies in the field for many years. A national scheme is being formed between the G.P.O., the Services, and the Mountain Rescue Committee so that radio communications may be linked on a wide basis rather than confined locally.

A wider review of mountain rescue may be obtained from the R.A.F. handbook Mountain Rescue, and from the handbook of the Mountain Rescue Committee (1965).

Much remains to be done to reduce the numbers of accidents on the hills, and many improvements in mountain rescue are required, but a host of willing volunteers in mountain-rescue teams, civilian and R.A.F., British Red Cross and St. John's Ambulance workers, and innumerable climbers, walkers, and police have given and continue to give help to those ill or injured in the mountains.

\section{Summary}

Increasing numbers of people are visiting the mountainous areas of Great Britain and about 200 accidents occur there each year. Mountain rescue services are organized by the Mountain Rescue Committee formed from mountaineering clubs in this country and from other outdoor organizations. An analysis of injuries due to mountain accidents in 1963 and 1964 shows that half the persons injured were 21 years old or less; injuries were equally distributed between walkers and climbers. Exposure and exhaustion occur frequently and could be avoided by climbers having better clothing and food supplies.

The author is grateful to his colleagues on the Mountain Rescue Committee for assistance in the preparation of this paper, to $\mathrm{Mr}$. H. K. Hartley, Secretary and Statistician, for statistical information, to Mr. O. O. Cowpe, Assistant Equipment Officer and Issuing Officer for Morphia, and Mr. A. I. L. Maitland, Equipment Officer for Scotland, for reading the manuscript, and to Mr. A. S. Pigott, O.B.E., Chairman, for much helpful advice.

\section{REFERENCES}

Brit. med. F., 1964, 2, 1279.

Edholm, O. G., Duff, D. G., Berkeley, J. S., Murray, W. H., and Blain, R. (1964). British Mountaineering Council Circular, November, 1964.

(1963). The Climber, October, p. 23. Maxwell, Castle Douglas.

Mountain Rescue Committee (1965). Mountain Rescue and Cave Rescue. Mountain Rescue Commitree, Hill House, Cheadle Hulme, Cheshire. Pugh, L. G. C. (1964). Lancet, 1, 1210.

Pugh, L. G. C. (1964). Lancet, 1, Mescue, May, A.M. 299. Air Ministry, London. 